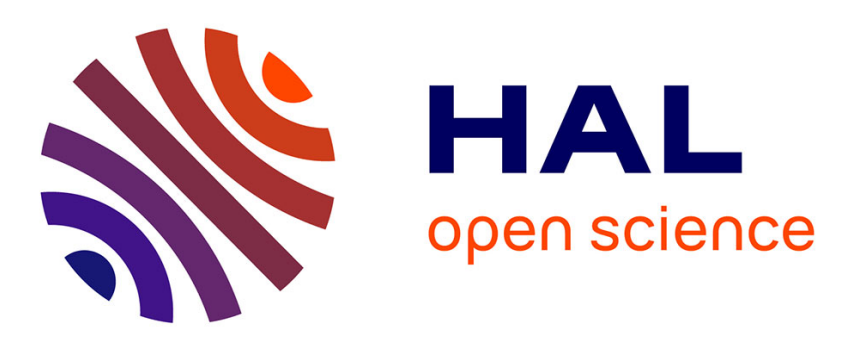

\title{
Effect of tip clearance and rotor-stator axial gap on the efficiency of a multistage compressor
}

\author{
Syed Noman Danish, Shafiq Rehman Qureshi, Malik Muhammad Imran, \\ Salah Ud-Din Khan, Muhammad Mansoor Mansoor Sarfraz, Abdelrahman \\ El-Leathy, Hany Al-Ansary, Mingshan Wei
}

\section{To cite this version:}

Syed Noman Danish, Shafiq Rehman Qureshi, Malik Muhammad Imran, Salah Ud-Din Khan, Muhammad Mansoor Mansoor Sarfraz, et al.. Effect of tip clearance and rotor-stator axial gap on the efficiency of a multistage compressor. Applied Thermal Engineering, 2016, 99, pp.988-995. 10.1016/j.applthermaleng.2016.01.132 . hal-01574153

\section{HAL Id: hal-01574153 \\ https://hal.science/hal-01574153}

Submitted on 11 Aug 2017

HAL is a multi-disciplinary open access archive for the deposit and dissemination of scientific research documents, whether they are published or not. The documents may come from teaching and research institutions in France or abroad, or from public or private research centers.
L'archive ouverte pluridisciplinaire HAL, est destinée au dépôt et à la diffusion de documents scientifiques de niveau recherche, publiés ou non, émanant des établissements d'enseignement et de recherche français ou étrangers, des laboratoires publics ou privés.

\section{(c)(1)}

Distributed under a Creative Commons Attribution| 4.0 International License 


\title{
Effect of tip clearance and rotor-stator axial gap on the efficiency of a multistage compressor
}

\author{
Syed Noman Danish, Shafiq Rehman Qureshi, Malik Muhammad Imran, \\ Salah Ud-Din Khan, Muhammad Mansoor Sarfraz, Abdelrahman El-Leathy, \\ Hany Al-Ansary, Mingshan Wei
}

\author{
Sustainable Energy Technologies Center, King Saud University, Riyadh, Saudi Arabia \\ National University of Sciences and Technology, PNS Jauhar, Karachi, Pakistan \\ Department of Mechanical Engineering, King Saud University, Riyadh, Saudi Arabia \\ Mechanical Power Engineering Department, Faculty of Engineering, El-Mataria, Helwan University, Cairo, Egypt \\ School of Mechanical Engineering, Beijing Institute of Technology, Beijing 100081, China
}

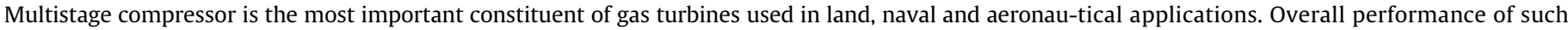

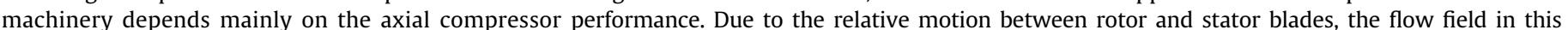

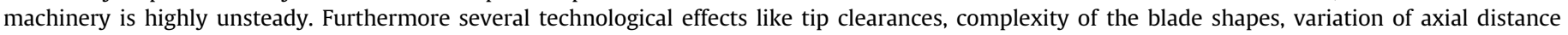

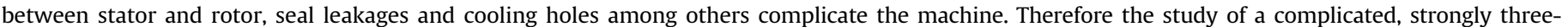

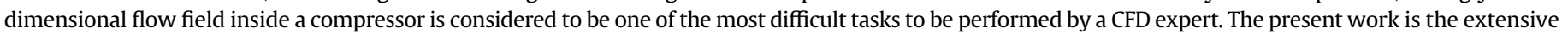

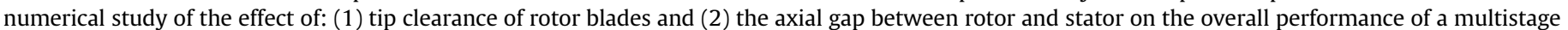

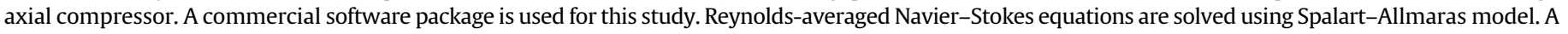

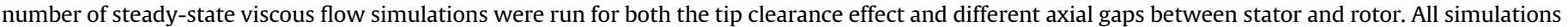

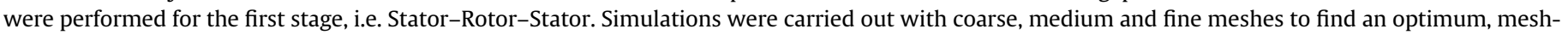

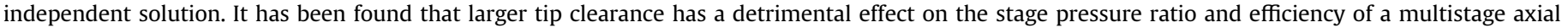

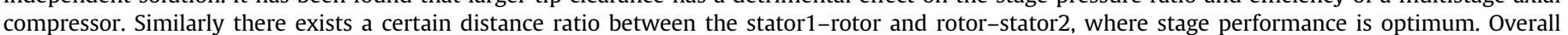

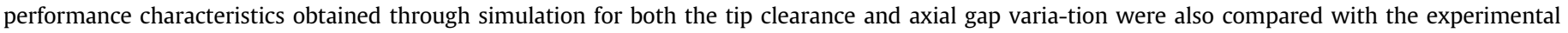
studies and found to be in good agreement.

\section{Introduction}

Apart from various industrial applications, the multistage axial compressor is the most important constituent of all gas turbine engines for land and aeronautical applications. Multi-stage axialflow compressors are normally used in high volumetric size applications, such as gas turbine engines. Overall performance of such machinery depends mainly on the axial compressor performance. Hence optimization of compressor design using different CFD tools has a great importance.

An axial compressor, like any other turbomachinery, is composed of several parts including stator/rotor blades, hub and shroud 
assemblies. Due to the relative motion between rotor and stator blades, the flow field in this machinery is highly unsteady. Furthermore several technological effects like tip clearances, complexity of the blade shapes, variation of axial distance between stator and rotor, seal leakages and cooling holes among others complicate the machine. Therefore the study of a complicated, strongly threedimensional flow field inside a compressor is considered to be one of the most difficult tasks to be performed by a CFD expert. However, it is important to know the characteristics of flow field due to its impact on efficiency, stability and operational range of the machine.

A survey of literature shows that there are three major effects caused by tip clearance. These effects are: (i) secondary flow due to pressure gradients; (ii) leakage flow through tip clearance due to pressure difference; (iii) the boundary scrapping effect due to blades moving relative to wall boundary layer. Hesselgreaves [1] gave a correlation to predict the efficiency drop of axial flow turbomachines. The study showed that an increase in tip clearance will have two distinct effects, i.e. reduction in work output and a reduced efficiency due to loss in kinetic energy through tip leakage flow. Lakshminarayana [2] through his study on axial compressor concluded that for low and moderate tip gap/chord ratio, there is a slight increase in the average lift. A substantial decrease in lift will only occur for relatively very high tip gap/chord ratio. Engin et al. [3] gave a very unique observation in which they concluded that there is no general agreement in terms of influence factors for tip clearance and they vary from one machine to the other. Tip clearance flow can be characterized in two ways. First is the flow blockage [4] and the second effect is the thermal loss as mentioned by Storer and Cumpsty [5]. Turbomachines often operate with a tip clearance larger than the design value due to the change in operating conditions as well as manufacturing limitations. A number of studies on tip clearance flow have been carried out in the past 60 years. Research carried out by Smith and Cumpsty [6] have shown a 23\% drop in pressure rise and a $15 \%$ increase in flow coefficient at stall conditions with an increase in tip clearance from $1 \%$ to $6 \%$ of blade chord. Ramakrishna and Govardhan [7] carried out numerical study to determine the effects of tip clearance in forward swept axial compressor rotors. Results showed that the increment in tip gap gradually affected the performance of the unswept blade while the effect was very high for the swept rotors. While carrying out study on high pressure compressor stage matching, Domercq and Escuret [8] and ZhengXian et al. [9] deduced that the tip clearance flows and its gap variation have a major impact on performance and stability of high pressure compressors. Tang et al. [10] predicted similar behaviour of loss in performance with an increase in tip clearance and they reported an optimum clearance of $6 \mu \mathrm{m}$ for their specific design. Sakulkaew et al. [11] found that for clearances gap (0.8\%-3.4\% span), efficiency is deteriorated with an increase in clearance. It is less sensitive to tip clearance for gaps greater than $3.4 \%$. Wei et al. [12] discussed the effects of contoured axisymmetric-casing on the blade tip-leakage flow.

Stator-rotor interactions are known to play a vital role in the overall performance of turbomachines. Furthermore, present day turbomachinery is being designed with the desire of minimizing blade-row spacing in order to reduce machinery length and weight and thus improved performance. Numerical study done by Deng et al. [13] explains how and why the tip leakage vortex trajectory of an axial compressor changes its shape with the change of gap size between the rotor and stator and its impact on rotor pressure rise characteristics. They found that the pressure rise increases monotonically with the decrease of upstream axial gap but no monotonic variation was observed with the change of downstream axial gap. Hence rotor performance was found to be more influenced by the upstream interaction than the downstream interaction. Experimental results from a four stage compressor achieved by Smith [14] and another multistage axial compressor experiment published by Mikolajezak [15] demonstrate that reducing the axial gap between blade rows in multistage compressors increase the pressure ratio and efficiency. In both cases efficiency was increased by $1 \%$ when the blades' rows were moved from far spacing to close spacing. One of the conclusions made by Roy et al. [16], while presenting their work on swept blades for axial flow fan/compressor, is that the efficiency is highly influenced by the axial gap between the rotor and stator and it decreased significantly with the increase in axial gap. Yoon et al. [17] studied the effect of stator hub configuration on the aerodynamic performance. They investigated the leakage loss and concluded that the design of clearance/span of the axial compressor is vital in optimizing the performance.

Results shown by the above studies and further investigations done by many more authors generally suggested the improvement in efficiency with the decrease in the axial spacing between the blade rows of an axial flow compressor. In contrast to the above phenomenon, an experiment done by Gorrell et al. [18,19] to investigate the effect of stator-rotor-stator axial spacing on performance of axial compressor proved that because of the formation of chopped bow shock, the losses in addition to mixing loss are present when the blade rows are spaced close together. These extra losses are associated with the upstream stator wakes. Measured data of this study showed that the axial spacing between an upstream stator and downstream transonic rotor has a noteworthy effect on stage performance. Mass flow rate, pressure ratio and efficiency decreased as the axial spacing between the upstream stator and downstream rotor was reduced. Outlet flow field of the multistage axial compressor with bowed stator stages was measured by Huawei et al. [20] using five hole probe under near stall conditions when rotor-stator axial gap was reduced by $33 \%, 67 \%$ and $100 \%$ of the original gap. They found that the overall performance increases within the main flow region as the rotor-stator axial gap of the compressor is decreased. They further concluded that the streamlines at the outlet of the bowed stator stages change little as the axial gap decreases, indicating that bowed stator stages will reduce the losses in the flow passage more effectively at reduced rotor-stator axial gaps.

Literature survey reveals that the tip clearance and axial gap has a very visible effect on efficiency and stability of compressors. The present work is the extensive numerical study of the effect of (1) the tip clearance of rotor blades and (2) the axial gap between rotor and stator on the efficiency of a multistage axial compressor. A commercial software package especially designed for turbomachinery flow field analysis has been used for this study. Reynolds-averaged Navier-Stokes equations are solved using SpalartAllmaras model for capturing turbulence. Air is used as a working fluid. A number of steady-state viscous flow simulations were run for both the tip clearance effect and also for different axial gap variations between stator and rotor. All simulations were performed for the first stage, i.e. stator-rotor-stator. Hub and shroud boundaries are kept unchanged. The simulations were run for many coarse and fine meshes in order to find an optimum, meshindependent solution.

\section{Computational methods}

The conservative form of Navier-Stokes equations can be written in the following generic equation:

$\frac{\partial U}{\partial t}+\frac{\partial F}{\partial x}+\frac{\partial G}{\partial y}+\frac{\partial H}{\partial z}=J$

where $\mathrm{U}, \mathrm{F}, \mathrm{G}, \mathrm{H}$ and $\mathrm{J}$ are the column vectors given by: 
$U=\left\{\begin{array}{c}\rho \\ \rho u \\ \rho v \\ \rho w \\ \rho\left(e+\frac{V^{2}}{2}\right)\end{array}\right\}$

$F=\left\{\begin{array}{c}\rho u \\ \rho u^{2}+p-\tau_{x x} \\ \rho v u-\tau_{x y} \\ \rho w u-\tau_{x z} \\ \rho\left(e+\frac{V^{2}}{2}\right) u+p u-\dot{q}_{x}-u \tau_{x x}-v \tau_{x y}-w \tau_{x z}\end{array}\right\}$,

$G=\left\{\begin{array}{c}\rho v \\ \rho u v-\tau_{y x} \\ \rho v^{2}+p-\tau_{y y} \\ \rho w v-\tau_{y z} \\ \rho\left(e+\frac{V^{2}}{2}\right) w+p v-\dot{q}_{y}-u \tau_{y x}-v \tau_{y y}-w \tau_{y z}\end{array}\right\}$,

$H=\left\{\begin{array}{c}\rho w \\ \rho u w-\tau_{z x} \\ \rho v w-\tau_{z y} \\ \rho w^{2}+p-\tau_{z z} \\ \rho\left(e+\frac{V^{2}}{2}\right) w+p w-\dot{q}_{z}-u \tau_{z x}-v \tau_{z y}-w \tau_{z z}\end{array}\right\}$,

$J=\left\{\begin{array}{c}0 \\ \rho f_{x} \\ \rho f_{y} \\ \rho f_{z} \\ \rho\left(u f_{x}+v f_{y}+w f_{z}\right)+\rho \dot{q}\end{array}\right\}$

where $\rho$ is the density, $u, v$ and $w$ are the components of velocity in the $x, y$ and $z$ directions respectively, $e$ is the internal energy per unit mass, $V$ is the velocity, $p$ is the pressure, $k$ is the thermal conductivity, $T$ is the temperature, $f$ is the body force per unit mass and $\dot{q}$ is the rate of volumetric heat addition per unit mass. In these equations, $\mu$ is the molecular viscosity and $\lambda_{2}$ is the second viscosity coefficient.

Solving Eq. (1) for turbulence requires very large computational facility and time. Alternately, we can use a Reynolds-averaged Navier-Stokes (RANS) equation which requires lesser memory and time with little effect on accuracy of the solution. RANS can be obtained by decomposing the dependent variables in Eq. (1) into two components: a turbulent fluctuation part and a time averaged component. For example a quantity $A$ can be decomposed as:

$A=\bar{A}+A^{\prime}$

where $\bar{A}$ is called time averaged value and $A^{\prime}$ is the fluctuating part. Solving Eq. (1) using Eq. (2) reveals the following momentum equation with constant density [21]:

$\rho \frac{\partial \bar{u}_{i}}{\partial t}+\rho \frac{\partial}{\partial x_{j}}\left(\bar{u}_{i} \bar{u}_{j}\right)=\frac{\partial}{\partial x_{j}}\left[\mu\left(\frac{\partial \bar{u}_{i}}{\partial x_{j}}+\frac{\partial \bar{u}_{j}}{\partial x_{i}}\right)-\rho \overline{u_{i}^{\prime} u^{\prime}}\right]-\frac{\partial p}{\partial x_{i}}$

Eq. (3) is identical to Eq. (1) with the exception of $-\rho \overline{u_{i}^{\prime} u_{j}^{\prime}}$. This term is known as Reynolds-stress tensor

$\tau_{i j}=-\rho \overline{u_{i}^{\prime} u_{j}^{\prime}}$
To close the system of RANS equations, $\tau_{i j}$ needs to be modelled. Boussinesq's eddy-viscosity concept [21] was one of the earliest proposed solutions to model $\tau_{i j}$, which gives the following relation:

$\overline{u_{i}^{\prime} u_{j}^{\prime}}=\frac{2}{3} K \delta_{i j}-v_{t}\left(\frac{\partial \bar{u}_{i}}{\partial x_{j}}+\frac{\partial \bar{u}_{j}}{\partial x_{i}}\right)$

where $K$ is the turbulent kinetic energy, $\delta_{i j}$ is the Kronecker delta, and $v_{t}$ is the eddy viscosity. Eq. (5) indicates that the turbulent nature of the flow can be modelled through $K$ and $v_{t}$. These parameters are termed as closure hypothesis or Turbulent Models. Although several turbulent models [22-24] have been developed, however, Spalart-Allmaras model [25] has been used in the present study.

A software package, FINE ${ }^{\mathrm{TM}}$ [26], developed by NUMECA [27] has been used to undertake the present study. Fine ${ }^{\mathrm{TM}}$ consists of three modules: geometry and grid modeller IGG ${ }^{\mathrm{TM}}$ [28], flow solver EURANUS $^{\mathrm{TM}}[29]$ and postprocessor CFView ${ }^{\mathrm{TM}}$ [30]. These three software systems have been integrated in a unique and user friendly GUI allowing complete simulations of 3D flow from the grid generation to the visualization.

Air as a real gas is assumed. Equation of state for a real gas is:

$p=Z \rho r T=Z \rho \frac{R}{M} T$

Here, $\rho$ is the air density, $r$ is the gas constant, $T$ is the absolute temperature, $R$ is the general gas constant, $M$ is the molecular weight and $Z$ is the compressibility factor.

Enthalpy is defined as:

$h=\int_{T_{0}}^{T} c_{p} d T=e+\frac{p}{\rho}=\int_{T_{0}}^{T} c_{v} d T+Z r T$

$\Rightarrow=\frac{\left(\int_{T_{0}}^{T}\left(c_{p}-c_{v}\right) d T\right)}{r T}$

It is very important in a numerical computation to place the first grid node off the wall within a certain range $\left(y_{\text {wall }}\right)$ because the viscous flow is accompanied with high gradients near wall due to formation of boundary layer. Therefore,

$y_{1}^{+}=\frac{\rho u_{\tau} y_{\text {wall }}}{\mu}$

where $y_{1}^{+}$is the wall variable for the first node off the wall. This variable is actually the local Reynolds number. Based on the experimental data of Lindgren, the value of $y_{1}^{+}$in the case of SpalartAllmaras model (at low Reynolds number) ranges from 1 to 5 . $u_{\tau}$ is the friction velocity defined as:

$u_{\tau}=\sqrt{\frac{\tau_{\text {wall }}}{\rho}}=\sqrt{\frac{1}{2} V_{\text {ref }}^{2} c_{f}}$

where $\tau_{\text {wall }}$ is the wall shear stress and $c_{f}$ is the coefficient of friction that can be related to Reynolds number using $1 / 7$ th velocity profile as:

$c_{f}=\frac{0.0227}{\operatorname{Re}_{x}^{1 / 7}}$

An alternative way to estimate $y_{\text {wall }}$ is to use the solution of Blasius equation with order terms neglected: 


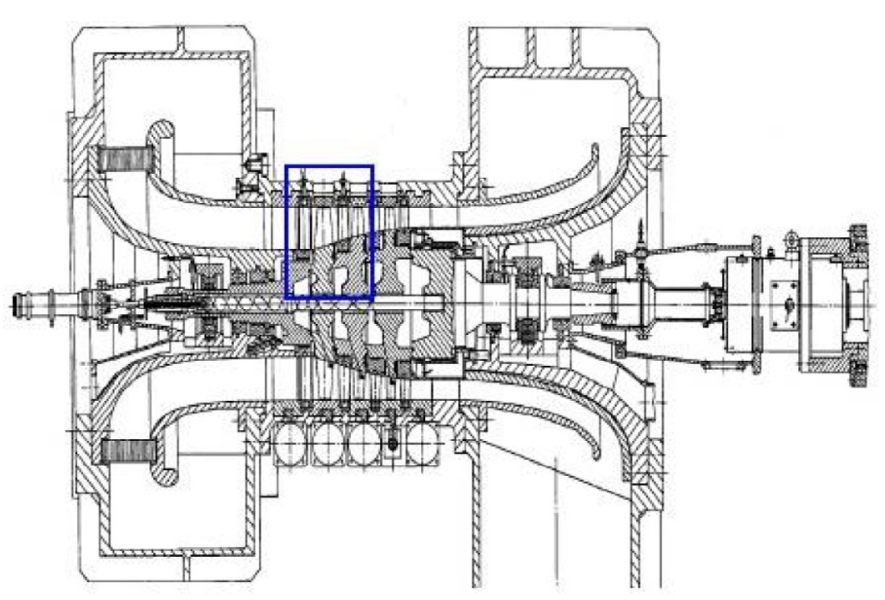

Fig. 1. Axial compressor under study [28].

$$
y_{\text {wall }}=6\left(\frac{V_{\text {ref }}}{v}\right)^{-\frac{7}{8}}\left(\frac{L_{\text {ref }}}{2}\right)^{\frac{1}{8}} y_{1}^{+}
$$

So there are two methods to calculate $y_{\text {wall. }}$. For the present study the $y_{\text {wall }}$ is calculated from both the methods and it comes out to be about $0.003 \mathrm{~mm}$. All the computational meshes presented have the same first node wall width of $0.003 \mathrm{~mm}$.

All the blocks for rotor are kept rotating at the design rotational speed, whereas the blocks for stator are kept stationary. Since both rotor and stator blocks are moving relative to each other therefore a rotor-stator $(\mathrm{R} / \mathrm{S})$ boundary is set with Full Non Matching Frozen Rotor Approach. The concept of frozen rotor approach consists of neglecting the rotor movement in the connecting algorithm. For rotor, the Reynolds averaged Navier-Stokes equations are solved in a rotating frame of reference, whereas the equations for the stator are solved in absolute frame of reference. The two solutions are literally connected while ensuring the continuity of velocity components and pressure.

Time-marching scheme was used in the flow solver. CFL number of 3 is kept in all computations. Multigrid strategy was employed for efficient and fast convergence. Central scheme is used for spatial discretization. The temporal discretization scheme used for the computations was an explicit multi-stage Runge-Kutta scheme.

\section{Geometry description}

The study deals with a 1-1/2 axial compressor stage, which is a part of a 3-1/2 stage axial compressor as shown in Fig. 1. This compressor has been designed by a reputed industry to be utilized in a jet propulsion system. The geometry of the compressor was available and the same has been selected as a test case for the present study. Both stators ( 38 and 40 blades) and rotor ( 25 blades) are cylindrical and twisted. The rotor is unshrouded with a design tip clearance of $0.3 \mathrm{~mm}$. During the subject study, it was varied from $0.003 \mathrm{~mm}$ to $2 \mathrm{~mm}$ to investigate the tip clearance effect on overall stage performance. Tip clearance for axial gap variation studies was kept fixed at $0.3 \mathrm{~mm}$.

\section{Grid generation}

The mesh was created using NUMECA's IGG ${ }^{\mathrm{TM}}$ [28] and AutoGrid ${ }^{\mathrm{TM}}$ [31]. AutoGrid ${ }^{\mathrm{TM}}$ is an automatic meshing scheme used for turbomachinery configurations. The software automatically generates mesh of a turbomachinery and an optimal control of orthogonality and quality of mesh is provided. A 3D view of one

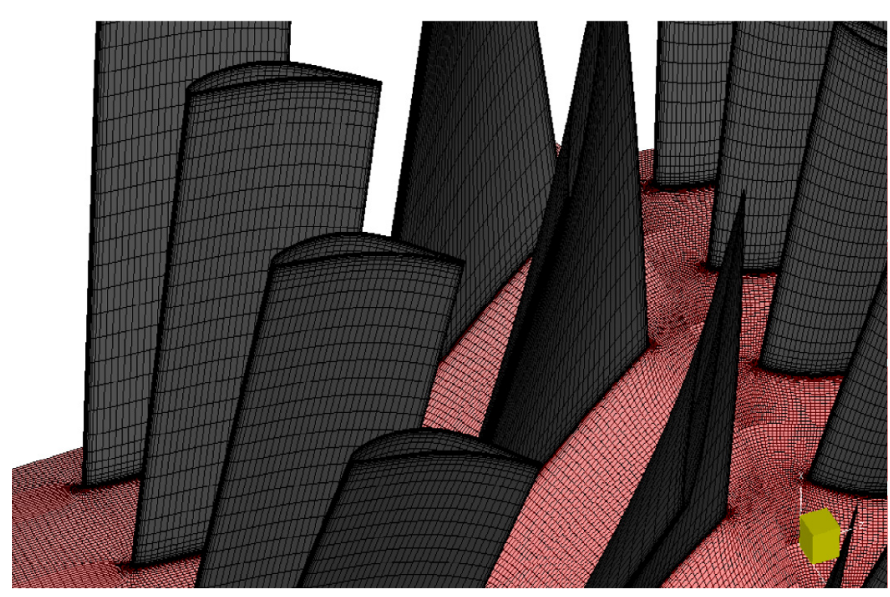

Fig. 2. 3D view of the stage indicating mesh.

of the stage meshes is shown in Fig. 2. The skin-topology includes 5 blocks as follows: The skin block is an O-mesh surrounding the blade. The inlet block is an $\mathrm{H}$-mesh located upstream the leading edge. The outlet block is an H-mesh located downstream the trailing edge. The up block is an $\mathrm{H}$-mesh located above the blade section. The down block is an H-mesh located under the blade section. Simulations were carried out with coarse, medium and fine meshes in order to find an optimum, mesh-independent solution, which obeys the criteria of $y_{1}^{+}$. The numbers of grid points in the blade-toblade topology were defined as: For row 1, the number of nodes was $21 \times 41 \times 17$. For row 2 , the number of nodes was $21 \times 53 \times 17$. For row 3 , the number of nodes was $17 \times 53 \times 41$.

\section{Results and discussion}

\subsection{Grid sensitivity analysis}

In order to achieve a mesh-independent solution, a number of simulations were run for coarse, medium and fine meshes. Table 1 provides the grid sensitivity analysis for one of the simulations which was done for tip clearance variation effects on axial compressor. It is observed that the percent error in stage total pressure ratio and efficiency is too small for medium level when compared with coarse and fine grid levels. Error values indicate that all three simulations are grid independent and any one of these three levels can be selected for the present study. Therefore, with a reasonable accuracy level and keeping in view the time required for complete simulation work, medium mesh level has been used for this study.

\subsection{Comparison of CFD results with experimental data}

A thorough experimental investigation of unsteady flow field of the axial compressor under present study has been carried out by Niehuis et al. [32] using pneumatic probes with high resolution in space. They have used miniaturized pitot and 3-hole pressure probes to investigate boundary layer both at hub and shroud. 5-hole pressure probes were applied to investigate flow phenomenon over the

Table 1

Grid sensitivity analysis.

\begin{tabular}{llllll}
\hline Grid level & $\begin{array}{l}\text { Grid points } \\
\text { (million) }\end{array}$ & $\begin{array}{l}\text { Pressure } \\
\text { ratio }\left(\Pi_{c}\right)\end{array}$ & $\begin{array}{l}\text { Efficiency } \\
(\eta)\end{array}$ & $\begin{array}{l}\text { \% Error } \\
\text { in } \Pi_{c}\end{array}$ & $\begin{array}{l}\text { \% Error } \\
\text { in } \eta\end{array}$ \\
\hline Coarse & 0.73 & 1.3062 & 88.019 & 0.097 & 0.163 \\
Medium & 0.97 & 1.3074 & 87.940 & 0.092 & 0.090 \\
Fine & 1.22 & 1.3087 & 88.083 & - & - \\
\hline
\end{tabular}


Table 2

Stage- 1 experimental data.

\begin{tabular}{lll}
\hline Stage 1 & Mass flow rate & Pressure ratio \\
\hline DP & 13.40 & 1.30 \\
OP1 & 13.66 & 1.31 \\
OP2 & 13.21 & 1.35 \\
OP3 & 8.35 & 1.18 \\
OP4 & 9.42 & 1.15 \\
\hline
\end{tabular}

blade. Experimental results extracted from this study are appended in Table 2 for stage- 1 .

In Table 2, DP is the designed operating point for stage- 1 of the selected axial compressor, and OP1, OP2 are the experimental operating points, very near to design speed. OP3 and OP4 are two operating points taken at $68 \%$ design speed, where results have been deduced by the experimental study.

Fig. 3 and Table 3 provide the comparison between numerical studies and experimental data. It indicates that the simulations are in good agreement with experimental results.

\subsection{Effect of variation in tip clearance}

Fig. 4 provides the stage total-to-total efficiency at various mass flow rates and tip gaps. The figure indicates that the stage efficiency increases as the tip gap decreases. Keeping in view both the efficiencies and the operating range, the tip gap of $0.1 \mathrm{~mm}$ seems to be the best choice. However it is practically difficult to maintain a gap of less than $0.3 \mathrm{~mm}$. So at tip gap of $0.3 \mathrm{~mm}$ the efficiency looks maximum compared to higher gaps. At tip gap of $2 \mathrm{~mm}$ both the operating range and the efficiency were significantly reduced. At $0.7 \mathrm{~mm}$ tip gap, the operating range is the highest as compared to all tip gaps; however, the efficiency is lower than the tip gap range of $0.003-0.3 \mathrm{~mm}$.

Fig. 5 provides the stage total-to-total pressure ratio at various mass flow rates and tip gaps. The figure indicates that the stage pressure ratio increases with the decrease in tip gap. Keeping in view

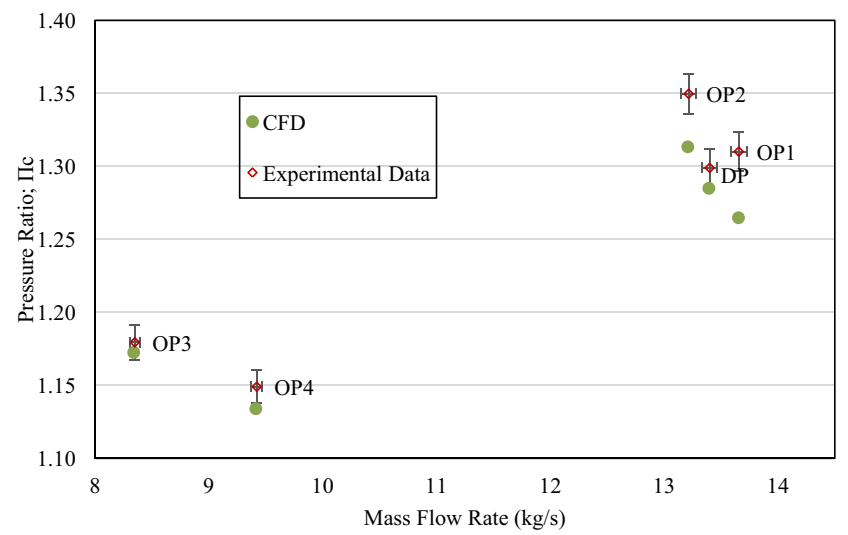

Fig. 3. Comparison of stage-1 numerical data with experimental results.

Table 3

Stage-1 results error analysis.

\begin{tabular}{lllll}
\hline Stage 1 & $\begin{array}{l}\text { Mass flow } \\
\text { rate }(\mathrm{kg} / \mathrm{s})\end{array}$ & $\begin{array}{l}\text { Numerical } \\
\text { pressure ratio }\end{array}$ & $\begin{array}{l}\text { Experimental } \\
\text { pressure ratio }\end{array}$ & Error (\%) \\
\hline OP1 & 13.66 & 1.25 & 1.31 & 4.28 \\
DP & 13.40 & 1.29 & 1.30 & 1.16 \\
OP2 & 13.21 & 1.30 & 1.35 & 3.36 \\
OP4 & 9.42 & 1.13 & 1.15 & 1.47 \\
\hline
\end{tabular}

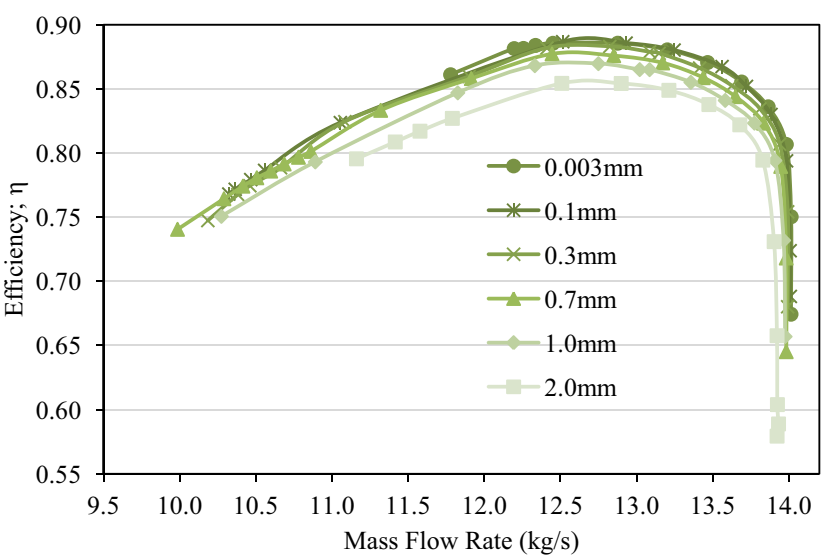

Fig. 4. Stage-1 total-to-total efficiency vs outlet mass flow rate for different tip gaps.

both the pressure ratio and the operating range, the tip gap of $0.1 \mathrm{~mm}$ seems to be the best choice. At tip gap of $2 \mathrm{~mm}$ both the operating range and the pressure ratio were significantly reduced. At $0.7 \mathrm{~mm}$ tip gap, the operating range is the highest as compared to all tip gaps; however, the pressure ratio is lower than the tip gap range of $0.003-0.3 \mathrm{~mm}$.

\subsection{Effect of variation in axial gap}

Based on experimental studies of Niehuis et al. [32], the designed axial gap between Stator 1 (IGV or S1) and rotor at shroud is $10.6 \mathrm{~mm}$, whereas axial distance between rotor and stator 2 is $13.3 \mathrm{~mm}$. This configuration has been simulated in the present study as a reference case and is denoted as standard case. Thereafter, axial distance between stator 1 and rotor was varied in four steps on either side (plus side and minus side) of the standard case, i.e. 2.5, 5.0, 7.5 and $10.0 \mathrm{~mm}$. Similarly axial gap between rotor and stator 2 was also varied for four equal steps on either sides of standard case, i.e. 2.5, 5.0, 7.5 and $10.0 \mathrm{~mm}$ as described in Table 4. In this way a total of 144 cases have been studied to know the effect of blades' axial gap variation.

Fig. 6 shows the effect on stage total-to-total efficiency, when S2 is kept at designed gap with respect to $R$ and distance between $S 1$ and $\mathrm{R}$ is varied at eight different locations, as mentioned in Table 4. The figure indicates the increase in stage efficiency with a

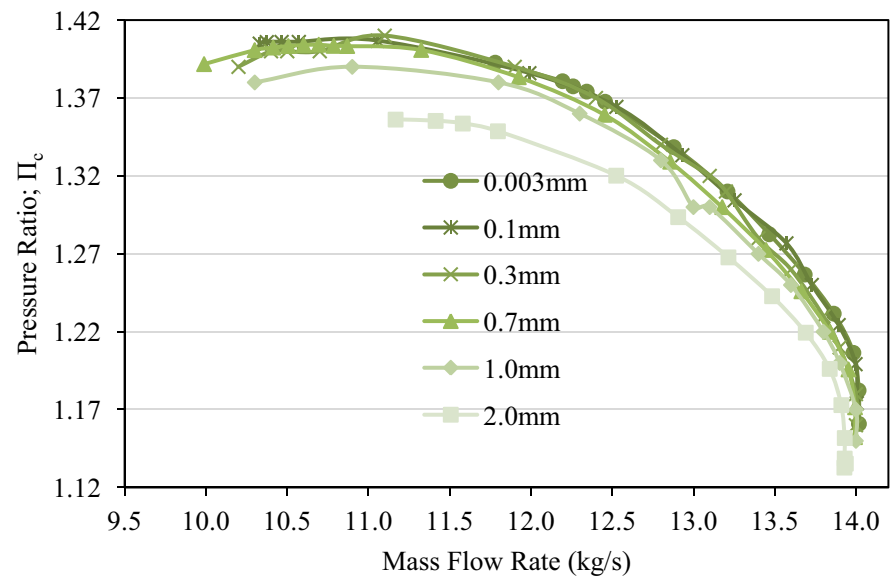

Fig. 5. Stage-1 total-to-total pressure ratio vs outlet mass flow rate for different tip gaps. 
Table 4

Description of cases for axial gap variation.

\begin{tabular}{lll}
\hline Gap increase $(\mathrm{mm})$ & $\begin{array}{l}\text { Axial gap between } \mathrm{S} 1 \text { and } \\
\mathrm{R}(\mathrm{mm})\end{array}$ & $\begin{array}{l}\text { Axial gap between } \mathrm{R} \text { and } \\
\mathrm{S} 2(\mathrm{~mm})\end{array}$ \\
\hline Designed gap & 10.6 & 13.3 \\
+2.5 & 13.1 & 10.8 \\
+5.0 & 15.6 & 8.3 \\
+7.5 & 18.1 & 5.8 \\
+10.0 & 20.6 & 3.3 \\
-2.5 & 8.10 & 15.8 \\
-5 & 5.6 & 18.3 \\
-7.5 & 3.1 & 20.8 \\
-10 & 0.6 & 23.3 \\
\hline
\end{tabular}

decrease in axial gap. Minimum axial gap $(-10 \mathrm{~mm})$ has maximum efficiency.

Fig. 7 shows the stage total-to-total efficiency, when S1 is kept at designed gap with respect to $\mathrm{R}$ and distance between $\mathrm{R}$ and S2 is varied at eight different locations. In this case all the graphs look to be bundled together. None of the gaps can be considered to give optimum result. So it can be concluded that this gap can be adjusted as per the design and manufacturing need as it does not affect the efficiency of the compressor.

Comparing Figs. 6 and 7, it is clear that the axial gap between $\mathrm{S} 1$ and $\mathrm{R}$ has some effect on overall stage efficiency as compared to the axial gap between $\mathrm{R}$ and $\mathrm{S} 2$.

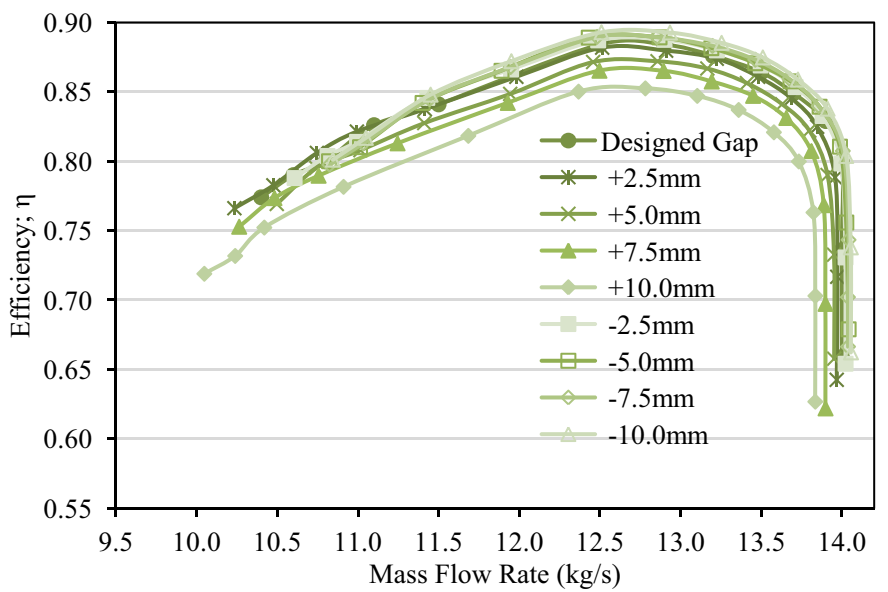

Fig. 6. Stage-1 total-to-total efficiency vs axial gap between $\mathrm{S} 1$ and $\mathrm{R}$.

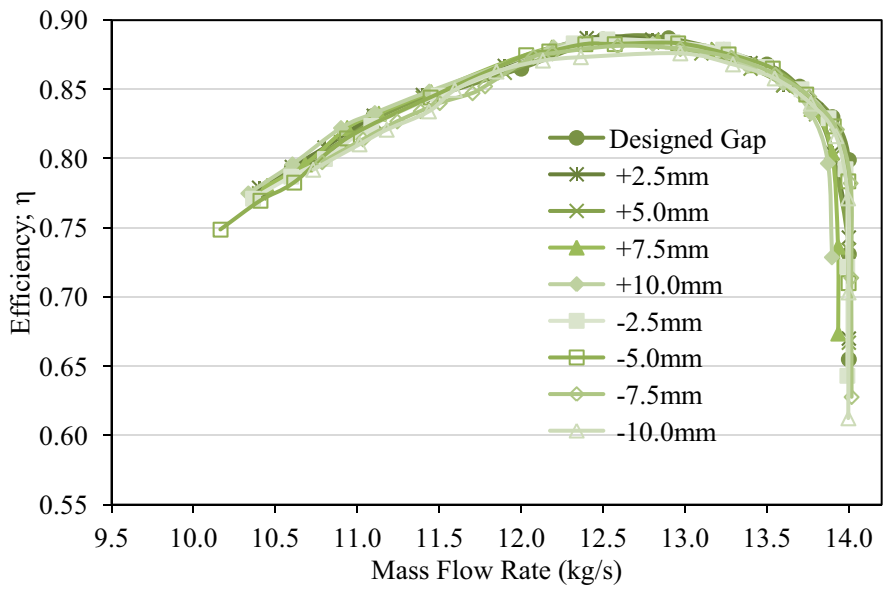

Fig. 7. Stage-1 total-to-total efficiency vs axial gap between R and S2.

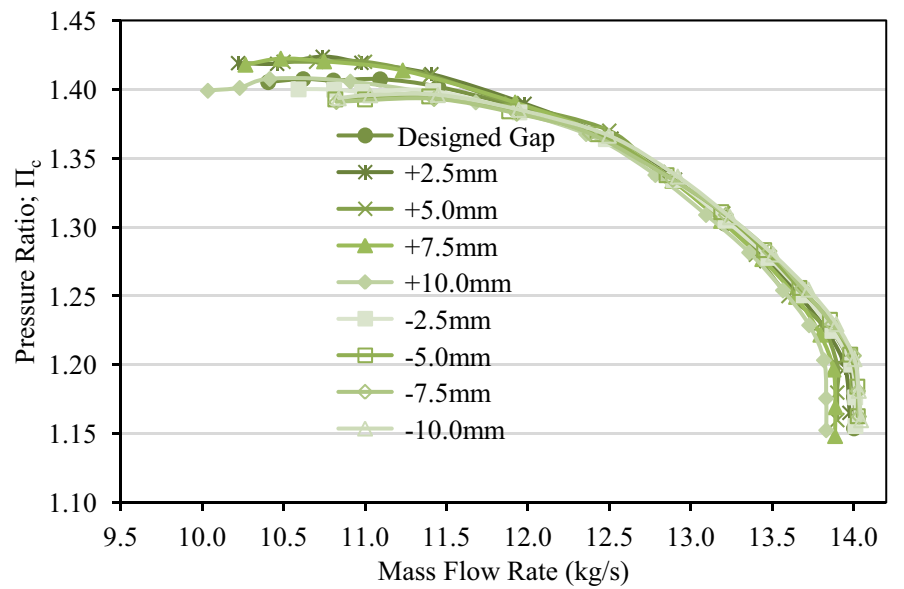

Fig. 8. Stage-1 total-to-total pressure ratio vs axial gap between $\mathrm{S} 1$ and $\mathrm{R}$.

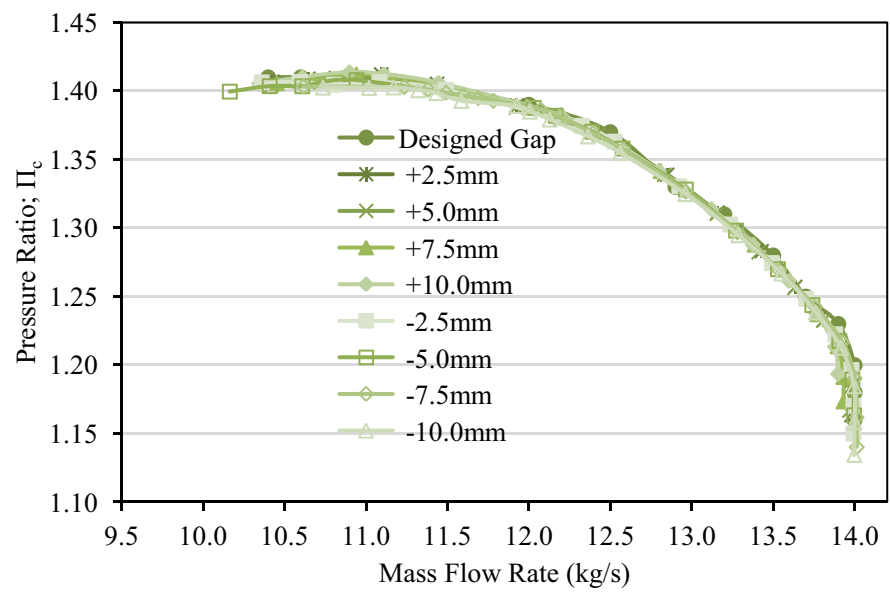

Fig. 9. Stage-1 total-to-total pressure ratio vs axial gap between $\mathrm{R}$ and $\mathrm{S} 2$.

Fig. 8 shows the effect on stage total-to-total pressure ratio, when $\mathrm{S} 2$ is kept at designed gap and distance between $\mathrm{S} 1$ and $\mathrm{R}$ is varied at eight different locations. Again a slight improvement in the stage pressure ratio is observed as the axial gap is reduced. However the pressure ratio marginally increases at surge point and decreases at choke point with an increase in axial gap.

Fig. 9 shows the effect on stage total-to-total pressure ratio, when $\mathrm{S} 1$ is kept at designed gap and distance between $\mathrm{R}$ and $\mathrm{S} 2$ is varied at eight different locations. Similar to Fig. 7 all the curves are bundled together, indicating almost identical behaviour except some variations at surge and choke regions.

Comparing Figs. 8 and 9, it is clear that the axial gap between $\mathrm{S} 1$ and $\mathrm{R}$ has more effect on overall stage pressure ratios as compared to axial gap variation between $R$ and $S 2$.

\section{Conclusions}

This paper presents a numerical study on the effect of varying tip clearance of rotor blades and the axial gap between rotor and stator on the overall performance of a multistage axial compressor, utilizing a commercial software package for solving the Reynoldsaveraged Navier-Stokes equations. The results of the present numerical simulations lead to the following main conclusions: 
1. Simulation results are in good agreement with experimental data. A maximum of $4.28 \%$ error in stage total-to-total pressure ratio was found near surge point.

2. Modelling of Reynolds averaged Navier-Stokes equations is found to be a practicable mean to study the complex behaviour of various design parameters of an axial compressor.

3. Increase in tip clearance has detrimental effect on the overall performance of an axial compressor. For the studied 1-1/2 stage, no optimum tip clearance, other than zero tip clearance, has been found. Keeping in view the stage efficiencies, stage pressure ratio, as well as the operating range, the tip gap of $0.1 \mathrm{~mm}$ seems to be the best choice. However it is practically difficult to maintain a gap less than $0.3 \mathrm{~mm}$. So at tip gap of $0.3 \mathrm{~mm}$ the performance looks optimum compared to higher gaps.

4. With fixed axial gap between $\mathrm{R}$ and $\mathrm{S} 2$, if the axial distance between $\mathrm{S} 1$ and $\mathrm{R}$ is decreased, it enhances the performance of the axial compressor. Whereas with fixed axial gap between $\mathrm{S} 1$ and $\mathrm{R}$, if the axial distance between $\mathrm{R}$ and $\mathrm{S} 2$ is decreased, it does not affect the performance.

\section{Acknowledgements}

The authors are grateful to the Deanship of Scientific Research, Research Center of College of Engineering, King Saud University for providing financial support.

\section{Nomenclature}

A

CFD

cfm

CFL

$D P$

$\Omega$

$c_{p}$

$c_{v}$

$c_{f}$

$d$

F

$i, j, k$

IGV

$k$

K

$m$

$M$

OP1

OP2

OP3

OP4

$p$

$p_{\text {ref }}$

$r$

$R$

Re

$s$

$S$
Area (geometric or flow area) $\left(\mathrm{m}^{2}\right)$

Computational fluid dynamics

Unit for volume flow rate $\left(\mathrm{ft}^{3} / \mathrm{min}\right)$

Courant-Friedrich-Levy

Designed operating point of selected compressor (13.4 kg/s)

Rotor angular speed

Specific heat at constant pressure $(\mathrm{kJ} / \mathrm{kg} \cdot \mathrm{K})$

Specific heat at constant volume $(\mathrm{kJ} / \mathrm{kg} \cdot \mathrm{K})$

Coefficient of friction

Distance to closest wall in Spalart-Allmaras turbulence model (m)

\section{Conservative fluxes}

Unit vectors in the $\mathrm{x}, \mathrm{y}$ and $\mathrm{z}$ directions respectively

Inlet guide vane, also mentioned as stator 1

Thermal conductivity $(\mathrm{W} / \mathrm{m} \cdot \mathrm{K})$

Turbulent kinetic energy (J)

Mass flow rate $(\mathrm{kg} / \mathrm{s})$

Mach number

Operating point of the selected compressor very near to DP (at mass flow rate of $13.66 \mathrm{~kg} / \mathrm{s}$ )

Operating point of the selected compressor very near to DP (at mass flow rate of $13.21 \mathrm{~kg} / \mathrm{s}$ )

3 Operating point of the selected compressor at $68 \%$ designed speed (mass flow rate of $8.35 \mathrm{~kg} / \mathrm{s}$ )

4 Operating point of the selected compressor at $68 \%$ designed speed (mass flow rate $9.42 \mathrm{~kg} / \mathrm{s}$ )

Static pressure $(\mathrm{Pa})$

Reference pressure (Pa)

Radius (m) or gas constant $(\mathrm{J} / \mathrm{kg} \cdot \mathrm{K})$

General gas constant $(\mathrm{J} / \mathrm{kg} \cdot \mathrm{K})$

Reynolds number

Entropy $(\mathrm{J} / \mathrm{kg} \cdot \mathrm{K})$

Vorticity magnitude in Spalart-Allmaras turbulence model Stator 1, also mentioned as IGV

Stator 2

Source term

The physical time (s)

Tip clearance gap in $\mathrm{mm}$
$T \quad$ Static temperature (K)

$U \quad$ Solution vector

$V \quad$ Volume

$V_{\text {ref }} \quad$ Reference velocity $(\mathrm{m} / \mathrm{s})$

$V_{t} \quad$ Tangential velocity $(\mathrm{m} / \mathrm{s})$

$V_{r} \quad$ Radial velocity $(\mathrm{m} / \mathrm{s})$

$W \quad$ Relative gas velocity $(\mathrm{m} / \mathrm{s})$

$x, y, z \quad$ Cartesian coordinates

$x_{c} \quad$ Axial clearance $(\mathrm{mm})$

$y_{c} \quad$ Circumferential clearance $(\mathrm{mm})$

$x_{\text {ref }} \quad$ Reference length (m)

$y_{\text {wall }} \quad$ Wall distance $(\mathrm{mm})$

$y_{1}^{+} \quad$ Wall variable for the first node off the wall

Z Gas compressibility factor

Greek symbols

$\rho \quad$ Density $\left(\mathrm{kg} / \mathrm{m}^{3}\right)$

$\eta \quad$ Efficiency (\%)

$\gamma \quad$ Ratio of absolute air angle $\gamma=a \tan \frac{V_{r}}{V_{z}}$

\section{References}

[1] J.E. Hesselgreaves, A correlation of tip clearance/efficiency measurements on mixed flow and axial flow turbimachines, in: Proceedings of 3rd Conference on Hydraulics Machinery, Budapest, Hungary, Sep 22-27, 1969.

[2] B. Lakshminarayana, Leakage and secondary flows in compressor cascades (Dissertation), Liverpool University, Liverpool, United Kingdom, 1963.

[3] T. Engin, M. Gur, R. Scholz, Effects of tip clearance and impeller geometry on the performance of semi-open ceramic centrifugal fan impellers at elevated temperatures, Exp. Therm. Fluid Sci. 30 (2006) 565-577.

[4] S.A. Khalid, The effects of tip clearance on axial compressor pressure rise (Dissertation), MIT, Cambridge, United States, 1995.

[5] J.A. Storer, N.A. Cumpsty, An approximate analysis and prediction method for tip clearance loss in axial compressors, J. Turbomach. 116 (1994) 648-656.

[6] G.D.J. Smith, N.A. Cumpsty, Flow phenomena in compressor casing treatment, J. Eng. Gas Turbines Power 106 (1984) 532-541.

[7] P.V. Ramakrishna, M. Govardhan, Stall characteristics and tip clearance effects in forward swept axial compressor rotors, J. Therm. Sci. 18 (2009) 40-47.

[8] O. Domercq, J.-F. Escuret, Tip clearance effect on high-pressure compressor stage matching, Proc. Inst. Mech. Eng. A J. Power Energy 221 (2007) 759-767.

[9] L. ZhengXian, P. Yan, Z. Mehrdad, On the nature of tip clearance flow in subsonic centrifugal, Sci. China Technol. Sci. 56 (9) (2013) 2170-2177.

[10] Y. Tang, C. Hung, Y. Chang, Performance improvements in low side scroll compressor with extended operation speeds, Appl. Therm. Eng. 31 (2011) 3542-3551.

[11] S. Sakulkaew, C.S. Tan, E. Donahoo, C. Cornelius, M. Montgomery, Compressor efficiency variation with rotor tip gap from vanishing to large clearance, J. Turbomach. 135 (2013) 35-48.

[12] Z. Wei, W. Qiao, P. Shi, P. Chen, L. Zhao, Tip-leakage flow loss reduction in a two-stage turbine using axisymmetric-casing contouring, Chin. J. Aeronaut. 27 (2014) 1111-1121.

[13] X. Deng, H. Zhang, J. Chen, Unsteady tip clearance flow in a low speed axial compressor rotor with upstream and downstream stators, in: ASME Turbo Expo 2005: Power for Land, Sea, and Air, Nevada, USA, Jun 6-9, 2005.

[14] L.H. Smith Jr., Casing boundary layers in multistage axial flow compressors, in: L.S. Dzung (Ed.), Proceedings of Symposium on Flow Research on Blading, Elsevier Publishing Company, 1970.

[15] A.A. Mikolajczak, The practical importance of unsteady flow, AGARD-CP-177, Unsteady Flow Phenomenon in Turbomachinery, Paper 1, 1976.

[16] B. Roy, M. Chouhan, P.M. Sivadas, Aerodynamic studies on swept blades for axial flow fan/compressor, in: National Conf. on Aerospace Eng., Ranchi, India, 2003.

[17] S. Yoon, R. Selmeier, P. Cargill, P. Wood, Effect of the stator hub configuration and stage design parameters on aerodynamic loss in axial compressors, J. Turbomach. 137 (2015) 091001

[18] S.E. Gorrell, T.H. Okiishi, W.W. Copenhaver, Stator-rotor interactions in a transonic compressor - part 1: effect of blade-row spacing on performance, ASME J. Turbomach. 125 (2) (2003) 328-335.

[19] S.E. Gorrell, T.H. Okiishi, W.W. Copenhaver, Stator-rotor interactions in a transonic compressor - part 2: description of a loss-producing mechanism, ASME J. Turbomach. 125 (2003) 336-345.

[20] L. Huawei, C. Fu, W. Jilin, W. Zhongqi, Flow field improvement by bowed stator stages in a compressor with different axial gaps under near stall condition, Chin. J. Aeronaut. 21 (2008) 215-222.

[21] J.D. Anderson Jr., Computational Fluid Dynamics: The Basics with Applications, McGraw-Hill, New York, 1995.

[22] B.S. Baldwin, H. Lomax, Thin layer approximation and algebraic model for separated turbulent flow, AIAA Paper No. 78-257, 1978.

[23] P.R. Spalart, S.R. Allmaras, A one-equation turbulence model for aerodynamic flows, AIAA Paper No. 92-0439, 1992. 
[24] K.Y. Chien, Predictions of channel and boundary-layer flows with a low-Reynolds number turbulence model, AIAA J. 20 (1) (1982) 33-38.

[25] B.E. Launder, B.I. Sharma, Application of the energy-dissipation model of turbulence to the calculation of flow near a spinning disc, Lett. Heat Mass Transf. 1 (1974) 131-138.

[26] NUMECA International, FINE ${ }^{\mathrm{TM}} /$ Turbo v7: flow integrated environment, User Manual, NUMECA International, Brussels, Belgium, 2006.

[27] NUMECA International, FINE/TURBO. <www.numeca.com>, (accessed 14.02.16)

[28] NUMECA International, IGG ${ }^{\mathrm{TM}}$ v5: interactive grid generator, User Manual, NUMECA International, Brussels, Belgium, 2006.
[29] A. Rizzi, P. Eliasson, I. Lindblad, C. Hirsch, C. Lacor, J. Haeuser, The engineering of multiblock/multigrid software for Navier-Stokes flows on structured meshes, Comput. Fluids 22 (1993) 341-367.

[30] NUMECA International, CFView ${ }^{\mathrm{TM}} \mathrm{v} 4$ : flow visualization and post-treatment User Manual, NUMECA International, Brussels, Belgium, 2006.

[31] NUMECA International, AutoGrid ${ }^{\mathrm{TM}}$ v5: automated grid generator for turbomachinery, User Manual, NUMECA International, Brussels, Belgium, 2006.

[32] R. Niehuis, A. Bohne, A. Hoynacki, Experimental investigation of unsteady flow phenomena in a three stage axial compressor I, Proc. Inst. Mech. Eng. A J. Power Energy 217 (2003) 217-341. 